\title{
Eี El entorno histórico económico de la evolución contable colegiada en Sonora, México. (1925-1994)
}

Economic environment collegial historical accounting developments in Sonora, Mexico. (1925-1994

\section{María Eugenia De la Rosa Leal ${ }^{1}$}

Juan José Gracida Romo

Resumen

La vida colegiada de los contadores públicos, es una fuen-

te importante de la historia moderna de la contabilidad en México, ya que el análisis y recapitulación de su trayectoria manifiesta momentos históricos de la profesión, a la vez que acumula acciones y comportamientos que hablan de
la vida económica de su contexto en un tiempo y momento.

Durante años México, ha tenido una fuerte influencia cultural y de inversión de su vecino norteamericano: EUA, en ello modelo continental anglosajón (Choi citado por De la Rosa 2000: 15) que distingue a EUA es seguido históricamente por México en una adaptación ad hoc con una relación teó rica permanente, que enfrenta un dilema dual por un lado beneficio inmediato de modernización y actualización de su estructura teórica contable; y por otro la diferencia cultural y de tipo de negocios que operan en México, que en algunos momentos hace inoperable conceptos contables sajones.

No obstante, se observa en la policromía cultural de Méxi co, como la tendencia del ejercicio profesional contable con lleva importantes grados de especialización y sofisticación tecnológica, en busca de generar información contable de la imagen fiel basada en normas reguladas por organismos profesionales exprofeso, en particular los Colegios de Contadores y el Instituto Mexicano de Contadores Públicos. En este trabajo, utilizando un análisis biográfico, documental y de caso, se presenta un extracto del hallazgo histórico de correlación entre el desarrollo contable del estado de Sonora en México y los distintos momentos economicos que los en cializacion comentando en cada periodo los cambios y especializaciones que se dieron. A fin de permitir conocer un panode la contabilidad regional en una histoi contemporanea

Palabras clave:

Contabilidad regional, historia económica, Sonora-México.

\section{Abstract:}

Collegial life of accountants, is an important source of modern history of accounting in Mexico, since the analysis and recap of his career shows historical moments of the profession, while accumulating actions and behaviors that speak of conomic life of its context in a time and moment.

For years Mexico has had a strong cultural and investment of its North American neighbor influence: the US, it accounts tinental model distinguishes USA is historically follown con Mexico in an ad hoc adaptation with a permanent theortica rexico in an ad hoc adaptation wis a permanent theoretica benefit of modernizing and updating its accounting theoretical structure; and other cultural and type of businesses operating in Mexico, which at times makes inoperable accounting concepts Saxons difference.

However, it is observed in cultural polychromatic Mexico, as the trend of accounting practice carries significant degree of specialization and technological sophistication, seeking to generate accounting information fairly based on standards egulated by professional bodies exprofeso, particularly Accountants associations and the Mexican Institute of Public Accountants.

In this paper, using a biographical documentary and case analysis, an extract of historical find correlation between ac counting development in the state of Sonora in Mexico and the different economic times that framed, commenting on each period changes and specializations presents they were given. In order to allow an overview of the road know, cir counts in contemporary history.

Keywords:

regional accounting, economic history, Sonora Mexico
En los últimos años la investigación sobre la historia de la contabilidad alrededor del mundo ha aumetado considerablemente, así vemos que en Inglaterra, Australia, Estados Unidos, Bélgica, Francia, Italia y España se ha instalado como una línea importante de la investigación en la historia. (Hernández,2010: 22-28)

En España, de hecho la historia de la contabilidad se ha convertido en uno vertiente importante de estudio por el número y calidad de las investigaciones realizadas. Mientras, por su parte en Mexico también han surgido en los últimos anos algunos investigadores pioneros en esta disciplina, con significativas participaciones en reuniones internacionales, pues hasta el presente se carece de un evento académico respecto a este género de la historia.

Una de las maneras de realizar la historia de la contabilidad en México, Es revisando la orientación y directrices del Instituto Mexicano de Contadores Públicos y sus colegios federados, ya que permite reconocer el discurso y justificación de los contadores públicos mexicanos, amén de reconocer la influencia de la variable económica en el modelo de intervención de los contadores en cada etapa histórica.

La historia de la contaduría colegiada en México se formaliza en 1925, al protocolizarse la escritura constitutiva del "Instituto" (Murrieta citado por Pintado, 1998:22) en la ciudad de México, momento en que se aprueban sus estatutos y fija como misión la unión de un gremio profesional, reunido y respetable. Los fundadores iniciaron de inmediato la difusión de reglas de operación, el estímulo a la investigación y el desarrollo de normas profesionales, entre ellas los principios de contabilidad y las normas y procedimientos de
auditoria, orgullo del ejercicio profesional independiente.

En ese momento la ciudad de México, era el centro económico y de estudio universitario del país, motivo por el cua conservó por casi 30 años su privacidad colegiada nacional. Conforme los contadores de comercio, privados y finalmente públicos emigraron o regresaron hacia los estados del interior del país se fue dispersando la semilla de la profesión colegiada, adoptando en cada región facetas particulares

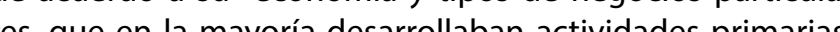
Poco a poco la Contaduría Pública en México fue cobrando presencia en diversas entidades federativas, tales como e Baja California, Nuevo León, y Sinaloa. A la par que en las universidades secambiol perfilformativo de los contador uniblicos, y se diversifica la participación de instituciones públicas y privadas que ofertan la licenciatura de contador público.

1De Computis on-line Revista Española de historia de la Contabilidad.
Así en 1958 en Hermosillo, Sonora, al noroeste del país frontera con los Estados Unidos de Norteamericana se constituye el Colegio de Contadores Públicos de Sonora, A.C. con una historia común: un grupo de contadores-amigos que unen sus entusiasmos para formar un organismo colegiado que enaltadores públicos de la región (De la Rosa \& Gracida, 2004:30).

El Colegio de Contadores Públicos de Sonora, se preocupó en ción con otras re giones y la capacitación profesional de sus socios para infundir un sello de calidad y distinción en los contadores públicos agremiados. Afiliándose al Instituto Mexicano de Contadores Públicos casi de inmediato, participando en la creación del Colegio de Contadores Públicos del Noroeste de Contadores Públicos, impulsando con esto desde la membresía local, un efecto en cadena del estado, a la región y el país, y en sentido inverso.

La historia de la contabilidad profesional regional con enfoque hacia la contabilidad empresarial, de gestión y de auditoria fiPúblicos de Sonora, al ser su presidente fundador el CP. D . Agustín Caballero Wario el primer director de la Escuela de Comercio de la Univeridad de Sonora en 1958 (De la Rosa \& Gracida, 2004: 22). Uniendo los caminos de la contaduría or ganizada con la formación universitaria de los contadores públicos de la región con un eje formativo de contador-auditor.

El desarrollo del Colegio de Contadores Públicos de Sonora, sigue en muchos sentidos caminos comunes a los de otros colegios similares en el país coordinados por el Instituto Mexicano de Contadores Públicos. Sin embargo, en cada periodo de gobierno de Colegio actúan como presidentes contadores distinguidos de la localidad, que tratan durante su periodo de gestion de proyectar su visión de la contabilidad y de las necesidades profesionales, sin lograr marginarse del efecto de la economía y cultura regional: mezcla de una cultura agropecuaria y minera, aunado a la influencia de los contadores de la frontera norte del pais, inmersos en negocios de exportación, viviendo realidades diferentes a los de la cd. De México, situada a más de $2000 \mathrm{kms}$. de distancia.

A la par el Instituto Mexicano de Contadores Públicos (IMCP) desde la ciudad de México va agremiando y respaldando las acciones de los nacientes colegios de la provincia del país, inserando poco a poco con paso firme la instiucionalidad conque enta frontera con Nortem arica toma espocial importania.

1. El entorno histórico de desarrollo contable en Sonora

El estado de Sonora, se ubica en el noreste de México en la frontera con Arizona, Estados Unidos, siendo el segundo estado en extensión en la República Mexicana, cuenta con varios recursos dada la diversidad de su geografía con una amplia costa, planicies costeras y una larga sierra, que forma la Sie- 
Reportes de investigación

actividad económica principal de Sonora fue la minería, en donde participaban, principalmente compañías norteamericanas, que tenían sus propias lineas de ferrocarriles, bancos y diversos tipos de
empresas (Gracida, 2002: 23). Sus contadores, eran principalmente norteamericanos, los que a su vez reportaban la información de las empresas al gobierno mexicano.

Antes del estallido de la Revolución Mexicana de 1910, se establecieron compañías deslindadores y de irrigación en los valles costeros de la planicie sonorense, principalmente en los valles del Yaqui y Mayo. Después de la Revolución en la década de los treinta y ante los efectos de la crisis económica de 1929 y su efecto en la minería, se toma el camino del desarrollo agropecuario, principalmente en el cultivo de los valles de la planicie. Razón por la cual en la década de los cuarenta, debido al impulso de la para la construcción de obras de irrigación (Gracida, 2002: 26) Su capital, Hermosillo, se transforma durante estos años con 1942, construyéndose edificios emblemáticos, que perdura a norte y se construyen nuevos boulevares que atraviesan de la capital, cercana al punto de unión de los ríos San Miguel y Sonora, instalando una planta productora de cemento, para abastecer la construcción de cines y edificios públicos. En este entorno de crecimiento del estado y la ciudad capital Hermosillo, se establecen nuevas empresas, que hacen necesaria la lega el primer contador público mexicano al Estado de Sonora: Dn. Agustín Caballero Wario, protagonista importante en la contaduría pública regional (De la Rosa \& Gracida, 2004: 47)

En México, la presencia de contadores públicos nacionales se presentándose el primer examen profesional de Contador Públcio y Administración en 1907 en la ciudad de México (Chávez \& Meneses; 2007:4-5). Es hasta el año de 1923 que se Constituye el Instituto de Contadores Públicos Titulado de México, antecedente del actual Instituto Mexicano de Contadores Públicos. En ese momento el Instituto Mexicano de Contadores Público ya constituido como organismo profesional colegiado, establePrincipios de Contabilidad Generalmente Aceptados, como parPe dus propuestas emblemáticas de la concepción contable.

La importancia del Instituto como órgano colegiado profesional rector se vio fortalecida en 1945 , con la aparición de la Ley de Profesiones y catorce años después con el de creto que dio origen a la auditoria fiscal establecida por el presidente Adolfo López Mateos que el 21 de abril de 1959 crea la Auditoria Fiscal Federal, que establece como únicos diversidad de proyectos empresariales y sociales. Y se funda hasta la actualidad. En Hermosillo se fundan nuevas colonias definen el trazo de la ciudad. Sin duda, una de las construcciones más importante es la primera presa en el estado al oriente inicia con la carrera de contador público de comercio en 1905 co Don Fernando Díez Barroso en la Escuela Superior de Comer- esponsables de su atención a los contadores públicos colegiados en exclusividad para dictaminar para efectos fiscales, los estados de la República Mexicana (Pintado, 1998: 18,32).

El primer contador público formado como tal en México, fue Ramón Cárdenas Coronado quién emigra hacia el noreste del pais fue en 1938, estableciéndose en Monterrey Nuevo León.

Poco a poco Hermosillo y el crecimiento económico de Sonora demandó contadores públicos locales. Así, Dn. Agustín Cabalero Wario con espiritu visionario se aboca a la formación de Escuela Superior de Contaduría en 1944, en la recién formada Universidad de Sonora. Hasta entonces, el Instituto de Contadores, había publicado el Primer Código de Ética Profesiona que regula la actividad contable (De la Rosa \& Gracida, 2004: 47). Anterior a esto en Estados Unidos de Norteamérica en 1934, se emiten los Principios de Contabilidad en el Boletín "Audits of Corporarte Accounts" para empresas que cotizaban en la Bolsa de Valores de New York, constituyendo un anteentido emite posteriormente el Instituto de Conta 1956 ante el crecimiento de el instituto de Contadores en como una primera versión nacional de los Principios de Contabilidad publicados en el Boletín no 2 de la Comisión de Principios de Auditoria (Buentello \& Márquez, 1986: 4).

Así, las cosas, en Sonora la formación de contadores universitarios se orientó a dar respuesta a las diferentes empresas que actuaban en diferentes ramos, principalmente el agricola, construcción, comercio y financiero. Teniendo su primer egresado titulado como contador público en la Universidad de Sonora en 955, el C.P. Jesús Hernández Saucedo. Para entonces el Institu de Contadores Públicos de México, había iniciado la afiliación de colegios estatales, entre ellos al Instituto de ContadoMonterrey y el Colegio de Contadores Públicos en 1949 (De la Rosa \& Gracida, 2004: 49).

En 1955 en Sonora, en el sur del estado, la actividad empresarial agrícola era muy fuerte en el valle del Yaqui debido a la ampliación de la frontera agrícola por la construcción de la presa Alvaro Obregón, propiciando la constitución del Instituto Sonorense de Contadores Públicos, en ciudad Obregón, Sonora. Para entonces, el crecimiento de las actividades empresariales habia nizacióndo creciendo en Hermosillo por el avance de la coloconocido como la costa de Hermosillo. Esto permitió a Hermosillo, crecer y convertise en el asiento de diferentes, empresas

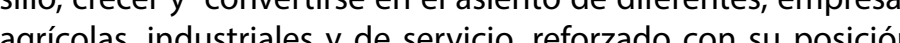

En nuestra localidad la historia del Colegio de Contadores de Sonora, se relaciona directamente con los primeros contadores públicos mexicano y el establecimiento de la ensenanza de la Contaduría Pública en el estado de Sonora. Lo anterior, en una coyuntura muy particular para el país y el escimiento económico y modernizó Sonora por la demanda de productos de la localidad y coincidió con la gubernatudel ex presidente de México Gral. Abelardo L. Rodríguez.

2. El espejo de la educación continua

La situación económica del estado de Sonora, ha requerido diversas habilidades y conocimientos en los contadores públicos profesionales, y asíse observa que la contaduría se especializa en de exportación, y en contabilidad de gestión en periodos de crisis y competencia global, olvidando en ocasiones los principios contables para permitir que el modelo contable anglosajon se influya fuertemente con la política económica que provoca que el ejercicio profesional y la contabilidad misma sea entendida como la herramienta necesaria para el pago de impuestos y los contadores fiscalistas rebasen en proporcion a los contadores nancieros y de gestión, cambiando el sentido de la contabilidad. Un análisis cercano a los programas de Educación Profesional Continua del Colegio de Contadores Públicos de Sonora, refleja la actividad económica latente del estado nos permite visualizar la interpretación de cada uno de los presidentes del Colegio en el ejercicio de su gestion.

Cuando el Colegio de Contadores Públicos de Sonora nace, e estado viene de vivir el desarrollo del modelo agricola de las estado viene de vivir el desarrollo del modelo agricola de las Para lo cual la estrategia económica fue el apoyo de la inversión federal y estatal en la creación de infraestructura hidráulica de comunicaciones lo que permitió la ampliación de la frontera agrícola. La concentración demográfica mas los cambios agricolas y pecuarios que tuvo Sonora en la segunda mitad de década de los cincuentas, fomento el desarrollo agrícola de la planicie costera sonorense ampliando los centros urbanos de Caborca, Hermosillo, Obregón y Navojoa integrándolos como zonas comerciales, de servicios y financieros, alrededor del de sarrollo agroindustria desarrollándose los molinos de trigo, Ia industria galletera la producción de pastas de sopa, la industria textil, y la alimenticia como la cerveza. Paralelamente crece actividad agropecuaria y con ella la ganadería de exportación estimulando un auge económico de centros urbanos como Agua Prieta, Hermosillo, Nogales, Ciudad Obregón y Navojoa.

En 1959 recién nacido el colegio de contadores Públicos de Sonora, se había llegado al límite de la expansión de la frontera agricola en el estado. La actividad agricola se transformaba de tipo extensivo a una de carácter íntensivo, lo que sibilidad de seguir extendiendo la fronter agrícola con tierras de irrigación y ante la baja de precio del algodón se dio inicio de irrigación y ante la baja de precio del algodón se dio inicio vo para el crecimiento del campo y la economí de Sonota.

Por otro lado la disminución de la inversión federal en la infraestos a los agricultores al vaivén del mercado internacional. Siendo estos temas los dominantes en la educación continúa del colegio.

4 / Trascender, Contabilidad y Gestió
En 1956-57 la actividad ganadera se expande requiriendo un fuerte apoyo contable financiero y de exportación pués del cese del brote de fiebre aftosa dado en 1947-1954.

En la década de 1960 el Colegio atraviesa por una etapa de eplanteamiento profesional mientras en la agricultura se incorpora un paquete tecnológico desarrollado en el Centro de Investigación Agrícola del Noroeste (CIANO), conocido como la "revolución verde" que creo nuevas variedades de trigo junto con una nueva tecnología de cultivo y nuevos procesos. Este

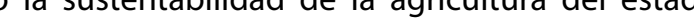
Mientras tanto, la actividad ganadera se expande con la exportación de becerros de engorda para los corra les de Estados Unidos y la actividad pesquera crece en los puertos sonornses, exiglendo modelos contables de ex-

expansion de la frontera agricolay Con la llegada al límite de la expansión de la frontera agrícola y norid del precio del algodón. El goben dodor del estado de sozacín en añ 1961 que tenia como objeto estimular fiscalmente a todas aquellas industrias de reciente creación y las que dores públicos fiscalistas.

Hacia finales de la década de los sesenta a la par de Sonora, el Colegio de Contadores Públicos experimenta un cambio importante en sus actividades económicas y profesionales, presenciando por un lado el establecimiento de la Industria Maquiladora en 1967 y por otro la diversificación de los productos pecuarios acordes a una nueva modalidad impuesta por el mercado norteamericano, se inicia con esto la industria maquiladora, que 位 de contabilidad por áreas de responsabilidad.

La industria maquiladora adquiere sus rasgos más signifCativos a partir de 1984-1985 con la llegada de la Ford Motor Company, de las franquicias a Sonora en Hermosillo y otras ciudades del estado, obligando al ejercicio profesional contable a incursionar en la globalización y utilizar con mayor A partir de la década de los 80 la industria maquiladora se convierA partir de la década de los 80 la industria maquiladora se convielida el proyecto industrializador de la maquila (1980 - 90), y aparece el sector servicios como el sector económico de mayor peso reafirmando su posición en el producto interno bruto del estado. Esta época se caracterizo por un alto índice inflacionario y obligo apoyada en ocasiones por valuadores y actuarios, lo cual implicó un manejo significativo de matemáticas y reglas de operación.

La labor profesional contable atiende el sector servicios, a partir de los 60's en giros como hotelería, banca, comercio y transporte, que se apuntalan en los 80's, usando técnicas de plan de cuentas especiales específicos para el giro, 
En los 90 's, mientras la industria maquiladora y de servicios se
van fortaleciendo, entra en crisis el sector agropecuario, la ganavan fortaleciendo, entra en crissis el sector agropecuario, la gana-
dería mantiene su alta tasa de crecimiento y culmina la modernización del sector ganadero. A la par, la agricultura y la pesca van en decadencia en razón de la crisis y el cambio del modelo económico en México, el cual se centró en el desarrollo de la industria de exportación, y obliga a los contadores públicos a manejar y conocer instrumentos financieros, aranceles, transferencia de tecnología y tratados tributarios.

En la década de 1990 la industria maquiladora en los puertos fronterizos se había convertido en la actividad motor del estado, principalmente en Nogales, San Luis Rió Colorado, Agua Prieta y Hermosillo ciudades que demandaban con fuerza la presencia profesional de contadores públicos y requerían que el program de educación continua del colegio capacitara en esos campos, nes del Colegio de Contadores Públicos de Sonora.

La pérdida de dinamismo del sector agropecuario se da cuando se agotan los éxitos de la revolución verde con las nuevas tecnologías de exportación agrícola y falta la inversión en infraestructura. Esta depresión agrícola se acentúa con el Tratado de Libre Comercio y la crisis económica nacional de 1994 que termin de dañar la agricultura sonorense, desviando los servicios contables tradicionales a estas áreas, en modelos mezclados que atienden contabilidades financieras, de gestión y de costos por areas, sin olvidar el manejo arancelario y de doble tributación. mento mantenía un modelo anglosajón conservador adaptado a las circunstancias de la región.

La crisis devaluatoria de 1994 provocó deudas impagables y la bancarrota de muchas uniones de crédito y cooperativas agrícolas, minando la fuerza de trabajo de los contadores públicos independientes y a la curricula universitaria de contadores públicos, que padecen una crisis de desempleo y sobreoferta.

Entre 1972 y 1994, la lista de crisis económicas nacionales, repercute localmente al Colegio cuya representación diezmada enfrenta con dificultad la sobrevivencia del gremio en activo, afectando la membresía y el espíritu del colegio.

Estas crisis fueron: 1972. La recesión económica general por bandonar el patrón monetario de divisas al dólar.

1980 - 1990. La década perdida. Sonora fue uno de los pocos estados que continuo con crecimiento económico a pesar de que el resto del país estaba estancado.

1994. El error de diciembre. Lleva a la devaluación de la moned y a las medidas de apoyo a la banca. Los bancos captan intereses desmedidos de interés sobre interés, lo que ha impedido hasta la fecha los créditos productivos.

En la actualidad, el crecimiento de la economía del país es débi y con ella la del estado de Sonora, a pesar de los esfuerzos gubernamentales y privados por estimular la economía. Por hoy a profesión contable y el Colegio de Contadores Públicos de Sonora comparten y tratan de estimular con su programa de educación continua el apoyo de las actividades económicas del estado y el auto empleo dividiendo su programa de educación continua en dos vertientes: la del compromiso federado con el Instituto Mexicano de Contadores Públicos; y la necesaria por la región que se va a aspectos partimariares impositivos y a explorar nuevos nichos de negocio. Con respecto a la institucionalidad, a partir de 1970 el Instituto Mexicano de Contadores Públicos desde la ciudad de Méxco establece y regula el funcionamiento de todos los colegios estatales, de forma tal que obliga a cumplir sus planes de capacitación y apegarse a sus normas y homologación como institución nacional representante de la profesion contable. Que ha incluido la Norma de Educación Profesional Continu (1974), como obligatoria para pertenecer a cualquier Colegio yer avala mo mo

\section{Conclusiones}

La contabilidad en México, se ha desarrollado adopterías $y$ propuestas norteam ha lo $\mathrm{XIX}$, sin que esta relación teórica

2. El modelo contable mexicano, corresponde al modelo anglosajón, tendiendo a especializaciones y sofisticaciones en el uso de técnicas y tecnologías. Este modelo se ha difundido y perfeccionado, a través de los colegios de contadores y las universidades que por natura leza han creado fuertes vínculos con sus colegios locales.

3. Los Colegios de Contadores concentran en su propia histoTha la evolución y trascendencia de la contabilidad en el pais. 4. El papel histórico del Instituto Mexicano de Contadores Públcos y los colegios federados en la contabilidad nacional, tomo fuerza a partir de que el Código Fiscal establece como requisto que el dictamen se emiriá por contadores púbicos colegidos, lo cual incentivó la adhesión a los colegios en formación. 5. Los colegios de contadores públicos, y en particular el Colegio de Contadores Públicos de Sonora ha sido sensibles a los cambios de la vida economica de la región, reflejando en sus progralíneas de conocimiento que han sido necesarias en un tiempo y mos de conocin histo que han sido nesas ias en un y rempo ción de los sectores agropecuario y minero principalmente.

6.ElColegiodeContadoresPúblicosesprotagonistadelaevolución visión y desarrollo de la contabilidad regional.Cumpliendo con su meta de representacióny calidad profesional del gremio contable.

7. La contabilidad en el estado Sonora ha evolucionado con la adopción de normas, la especialización fiscal y en auditoría Siendo su diferencia más tajante el uso de medios electrónicos que sustituyen y ponen en conflicto la importancia de la evidencia objetiva y documentada de las operaciones realizadas.

\section{Concluyendo:}

La historia moderna de la contabilidad en México, tiene tres constantes en su evolución y cambio: el contexto de la política económica, la influencia norteamericana y la cambiante política tributaría del país.

La evolución de la contabilidad encontrada en Sonora se resume en: complejidad legal y tributaria, convencimiento del uso de normas de información financiera, manejo de modelos $d e$ gestión, técnicas de evaluación y proyección financiera. A la vez de exigir a partir de la firma del Tratado de Libre Comercio como cimiento del idioma ingles y uso de nuevas tecnologías.

El Colegio de Contadores Públicos de Sonora actúa como catalizador receptor y transmisor de nuevos conocimientos y habilidades contables en la región.

\section{Referencias}

Buentello Garza, Ovidio y Márquez González, Humberto. (1986). Los principios de contabilidad: su evolución y trascendencia en las decisiones. Revista Contaduría Pública. Agosto. Instituto Mexicano de Contadores Públicos. Pp: 4-19.

De Computis on-line Revista Española de historia de la Contabilidad
De la Rosa Leal, María Eugenia y Gracida Romo, Juan José. (2004). "Una Historia en Curso", Hermosillo, Sonora, México: Colegio de Contadores Públicos de Sonora, A.C.

De la Rosa Leal, María Eugenia. (2000). Un modelo contable nacional en el 2000. Revista Vértice Universitario. (Año 2 No. 7). Universidad de Sonora, México. Pp: 11-16.

Chávez Huitrón, David y Meneses Martínez, Alma F. (Coordinadores). (2007). 100 anos de la Contaduría en México, México: Instituto Mexicano de Contadores Públicos de México.

Gacida Romo, Juan José (2002). "Hacia una Historia Económica del siglo XX sonorense" en Revista Vértice Universitario, no.15: Hermosillo, Sonora, México: Universidad de Sonora, julio-sep-

Hernández Esteve, Esteban, La Historia de la Contabilidad, vía privilegiada de aproximación a la investigación histórica. Cuenta de Espana para financiar la guerra de Felipe ll co los Reinos Pabs IV y Erique II Francia (1556-1559) Rea Aca eapa Doctores de España, 2010

Pintado Nieto, José Manuel C.P. (1998). ESO FUIMOS.ESTO SOMOS. (n) Mexicano de contadores Públicos, A.C 